\title{
Diagnosis of $O$. volvulus infection via skin exposure to diethylcarbamazine: clinical evaluation of a transdermal delivery technology-based patch
}

\author{
K. Awadzi ${ }^{1 \wedge}$, Nicholas O. Opoku', Simon K. Attah ${ }^{1,2}$, Janis K. Lazdins-Helds ${ }^{3}$ and Annette C. Kuesel ${ }^{3^{*}}$ (D)
}

\begin{abstract}
Background: Elimination of onchocerciasis in Africa is now regarded as an achievable goal in many areas. This makes monitoring changes in infection prevalence a key component of control programmes. Monitoring is currently based on determining the presence of $O$. volvulus microfilariae in skin snips, an invasive, labour-intensive method. The Onchocerciasis Control Programme (OCP) had established procedures to detect O. volvulus infections via the localized skin reaction induced by killing of microfilariae upon skin exposure to diethylcarbamazine via a patch (OCP-patch). Large scale OCP - patch use is difficult due to labour-intensive patch preparation. At the request of TDR, a manufacturer specialized in transdermal-delivery systems developed a ready-to-use diethylcarbamazine (DEC) containing patch (LTS-2 patch). To qualify this patch for large scale studies of its sensitivity and specificity, this study evaluated its ease of application, ability to detect infection and DEC exposure related adverse reactions compared to the OCP-patch in 30 infected individuals.
\end{abstract}

Methods: Each participant with 0.2-36.8 O. volvulus microfilariae/mg skin received the OCP-patch and 4 days later the LTS-2 patch at the left and right iliac crest, respectively, for $24 \mathrm{~h}$. Presence and characteristics of local skin reactions were assessed at patch removal and $6 \mathrm{~h}$ later. Skin reaction and Mazzotti reaction rates were compared with Fisher's exact and a paired t-test, respectively.

Results: The LTS-2 patch could be applied within 10 s. Mild itching occured at $63.3 \%$ of OCP-patch (duration $8.9 \pm 11.8 \mathrm{~h}$ ) and $26.7 \%$ of LTS-2 patch sites (duration $1.0 \pm 2.5 \mathrm{~h}$ ) and was the most frequent Mazzotti reaction. At patch removal after $24 \mathrm{~h}$, a diagnostic local skin reaction was present under $90 \%$ of OCP-patches and $83 \%$ of LTS-2 patches; 6 h later, it was present at $93 \%$ of OCP-patch and $100 \%$ of LTS-2 patch sites.

Conclusions: The data suggest that safety, tolerability and ability to detect infections of the LTS-2 patch are comparable to those of the OCP-patch. They qualify the LTS-2 patch for field studies to determine LTS-2 patch sensitivity, specificity and utility during large scale use and thus to inform use of the LTS-2 patch by onchocerciasis control programmes to determine prevalence of infection.

Trial registration: Current controlled Trials ISRCTN76875372.

Keywords: Africa, Onchocerciasis, Diethylcarbamazine patch, Diagnosis, Transdermal-delivery

\footnotetext{
* Correspondence: kuesela@who.int

Deceased

${ }^{3}$ UNICEF/UNDP/World Bank/WHO Special Programme for Research and

Training in Tropical Diseases, World Health Organization, Geneva, Switzerland

Full list of author information is available at the end of the article
} 


\section{Background}

Onchocerciasis is caused by the filarial nematode Onchocerca volvulus. The parasite is transmitted between humans through blackfly vectors, in Africa mainly by Simulium damnosum s.l. The African Programme for Onchocerciasis Control (APOC) estimated 89 million Africans at risk and 37 million infected in central and east Africa [1] based on rapid epidemiological mapping [2]. In 2010, the population in the APOC target area living in meso-endemic and hyperendemic areas was estimated to be 32.4 Million and 31 Million, respectively [3]. In the 13 endemic foci in 6 countries in Central and South America, the population at risk was estimated to be 0.56 million people living in an estimated 1939 communities of which 63 and $25 \%$ were hypo- and meso-endemic, respectively. Since 2000, between 17-25 rounds of semi-annual treatment with ivermectin, complemented in 138 hyperendemic communities for several years by two additional treatments/year, have resulted or are likely to have resulted in interruption of transmission in 11 foci [4].

The feasibility of elimination of onchocerciasis through long term mass treatment with ivermectin in Africa has been demonstrated in Senegal and Mali [5, 6]. Significant reduction in prevalence of infection in children or adults after 5-13 years of annual community directed treatment with ivermectin has been shown in Cameroon, Uganda and Nigeria [7-9]. Consequently, the objectives of APOC have been expanded from control of onchocerciasis as a public health problem to elimination of onchocerciasis where feasible [10]. This requires large scale monitoring of the prevalence of current infection in areas undergoing mass treatment. Furthermore, there is a need to determine the prevalence of onchocerciasis in hypoendemic areas which are not yet included in onchocerciasis control activities to decide on the appropriate strategy to eliminate onchocerciasis. This requires diagnostic tools which are suitable for large scale use in communities.

Currently, the standard method for diagnosis of patent infection is "skin snipping". This procedure demonstrates the presence of the microfilariae $(\mathrm{mf})$ of $O$. volvulus in pieces of skin snipped (skin snips) from selected areas of the body. The results are quantifiable and are usually expressed as $\mathrm{mf} / \mathrm{mg}$ skin in clinical studies where weighing of snips is feasible (see e.g. [11-13]) or $\mathrm{mf} / \mathrm{snip}$ in field based studies (see e.g. [7, 14]). The main limitations of skin snipping are the need for trained personnel and special equipment (skin snip punches, microscopes, equipment for sterilization to avoid transmission of blood-borne pathogens and sometimes, field generators). Additional drawbacks are the inability to detect pre-patent and very light infections. Furthermore, communities and volunteers may accept the snipping only grudgingly or not at all. Thus, skin snipping is not suitable for large scale monitoring.
The presence of $\mathrm{mf}$ in the skin can be inferred by demonstrating the well-known events (Mazzotti reactions) that follow their destruction by diethylcarbamazine (DEC), such as itching, rash and lymphadenitis. Initial approaches used one oral $50 \mathrm{mg}$ dose of DEC. This procedure, known as the Mazzotti test, is sensitive but yields a small number of both false positive and false negative reactions. A potential for false positive reactions is the presence of dermal $\mathrm{mf}$ other than $O$. volvulus that are sensitive to DEC (eg: Mansonella streptocerca). The key aspects of the Mazzotti test have been summarised previously $[15,16]$.

A major limitation of the oral Mazzotti test is the potential for severe or even serious systemic adverse reactions to the killing of the microfilariae and ocular damage in heavily infected individuals [17-19]. The test is, therefore, recommended only for individuals in whom a diagnosis of onchocerciasis is strongly suspected but $\mathrm{mf}$ cannot be detected despite a detailed search in the skin and eyes [20, 21]. To avoid the systemic effects of oral administration, DEC has been applied topically to a small area of skin after dispersion in diverse excipients that facilitate drug penetration through the skin. The killing of $\mathrm{mf}$ is accompanied by a local skin reaction, a Mazzotti reaction, which has been validated as a surrogate marker of infection [22-24]. This diagnostic procedure is referred to as the "DEC patch test." The Onchocerciasis Control Programme of West Africa (OCP) introduced a patch containing $20 \% \mathrm{w} / \mathrm{v}$ DEC in a commercially available skin lotion (OCP-patch) as a safe, cheap, non-invasive and specific diagnostic test for monitoring O. volvulus infection [25-27]. A review of the experiences and considerations that led to the DEC patch test has been provided by Ozoh et al. [28].

Other diagnostic methods have been developed. Detection of $O$. volvulus DNA via polymerase chain reaction $[29,30]$ or O. volvulus antigens via immunoblotting [31] or a dip-stick assay [32] identifies current infection but requires tissue/blood samples, specialised laboratories, is expensive and not yet available for point-of-care use. Immunological assays based on antibody detection cannot differentiate previous from patent infections [33, 34] but will be valuable for surveillance for recrudescence of infection after the decision to stop ivermectin treatment in a transmission zone. A format to detect antibodies to the antigen Ov16 that does not require specialized laboratories and can be used as a 'point-of-care' diagnostic in the field was developed by PATH, funded by the Bill and Melinda Gates Foundation, and is now commercially available through Standard Diagnostics, Inc. (http:// sites.path.org/dx/ntd/oncho/, http://www.path.org/news/ press-room/703/ accessed 23 March 2015).

The main disadvantage of the OCP-patch is that it requires ad hoc preparation, i.e. dispersion of DEC in 
Nivea lotion that is then applied to a piece of filter paper and attached with a strip of adhesive plaster to the skin, a very labour intensive procedure for large scale use [26, 27]. Furthermore, neither concentration or homogeneity of the DEC containing lotion nor a standardized amount of the lotion on the filter paper can be assured. These disadvantages could be overcome by a DEC patch manufactured according to current 'Good Manufacturing Practices' [35] with a standardized DEC content and transdermal delivery capacity.

At the request of OCP and APOC, the UNICEF/UNDP/ World Bank/WHO Special Programme for Research and Training in Tropical Diseases (TDR) approached researchbased pharmaceutical groups specialized in drug transdermal delivery technologies for their willingness to develop a DEC patch for the onchocerciasis control programmes free of charge and in the context of lack of commercial potential of the patch. LTS Lohmann Therapie Systeme AG (LTS) was willing to develop a DEC patch in this context. The research and development programme conducted by LTS yielded a patch (LTS-2 patch) optimized for DEC content and skin permeation rates. In an in vitro system, approximately $50 \mu \mathrm{g} / \mathrm{cm}^{2}$ of DEC from the LTS-2 patch had permeated through human skin after $3 \mathrm{~h}$ and $500 \mu \mathrm{g} /$ $\mathrm{cm}^{2}$ after $24 \mathrm{~h}$ (unpublished results).

The LTS development programme was complemented by a TDR sponsored clinical evaluation. The endpoints allowed the indirect assessement of whether the extent of DEC permeation into the skin from the LTS-2 patch was clinically significantly above or below that from the OCP patch: a significantly higher extent of DEC permeation would be indicated by significantly more frequent and/or more severe Mazzotti reactions and/or a local skin reaction extending further beyond the patch area than seen after the OCP-patch, while a significantly lower extent of DEC permeation would be indicated by a significant number of people with a local skin reaction after the OCP-patch, but no local reaction after the LTS-2 patch. Results from this clinical evaluation suggesting comparable DEC permeation would qualify the LTS-2 patch formulation for large scale evaluations of its sensitivity and specificity, otherwise, a new formulation of the patch would have to be developed with either increased or decreased DEC penetration into the skin. The clinical evaluation of the LTS-2 patch was conducted at the Onchocerciasis Chemotherapy Research Center (OCRC), Hohoe in Ghana.

This report describes the results of this evaluation in 30 participants known to be infected based on O. volvulus microfilariae detection in skin snips. The primary objective was to assess the safety and tolerability as well as the potential field utility (ease of application, presence and readout of diagnostic skin reaction) of the LTS-2 patch in comparison with the OCP-patch. Secondary objectives were (a) to compare the rate of positive skin reaction of the OCP-patch and the LTS-2 patch 24 and $30 \mathrm{~h}$ after application and (b) to determine the underlying pathology of the skin reactions from the histopathology of skin punch biopsies taken from selected participants.

\section{Methods}

\section{Ethical approval and informed consent}

The study protocol and informed consent documents were approved by the Ethics Committee of the Ghana Health Service and by the Secretariat Committee for Research Involving Human Subjects of the World Health Organization.

The information document that detailed all aspects of the study was read to and discussed with the community in the community in the local language (Ewe). Each participant signed or thumb printed an informed consent certificate approved by the Ethics Committees and received a copy of the informed consent document. An impartial witness and the investigator present during the meetings and discussions (KA or NOO) countersigned and dated the certificate.

The study took place at the OCRC, Hohoe, in Ghana in May and June 2006 and was conducted in accordance with good clinical practice, the Declaration of Helsinki (2000 revision) and all applicable local regulations.

\section{Study participants}

Thirty men and women were recruited from onchocerciasis endemic communities in the basin of River Tordzi located in south-eastern Ghana $\left(0^{\circ} 30^{\prime}\right.$ to $0^{\circ} 45^{\prime} \mathrm{E}, 6^{\circ}$ $45^{\prime}$ to $7^{\circ} 0^{\prime} \mathrm{N}$ ). During the study, ivermectin mass distribution had not yet been initiated because the area is overall hypoendemic with small meso- or hyperendemic foci [13]. Eligible participants were between 18 and 55 years with a body weight $\geq 40 \mathrm{~kg}$ and in good general health as determined by medical history, physical examination, electrocardiograms (ECGs) and clinical laboratory evaluations (see Table 1). The skin $\mathrm{mf}$ density determined as the arithmetic mean of the $\mathrm{mf}$ count/mg skin in one snip each from the right and left iliac crest was required to be low ( $>0-20 \mathrm{mf} / \mathrm{mg}$ ), since the primary concern was that the amount of DEC penetrating through the skin $(\leq 6.2 \mathrm{mg}$, see below) would be insufficient to elicit detectable skin reactions. In contrast, the potential for severe reactions in multiple body systems as reported after systemic administration of DEC to highly infected people was not considered a concern. Studies of oral DEC administration to O. volvulus infected people have shown that the severity of Mazzotti reactions is related to the number of microfilariae killed, which depends on the intensity of infection pretreatment and the dose of DEC [36-38]. The $\leq 6.2 \mathrm{mg}$ DEC in the LTS-2 patches (see below) is substantially 
Table 1 Safety and efficacy evaluations

\begin{tabular}{|c|c|c|c|c|c|c|c|c|c|c|}
\hline Study day & -5 to -1 & 1 & 2 & 3 & 4 & 5 & 6 & 7 & 8 & 9 \\
\hline Medical and medication history & $x$ & & & & & & & & & \\
\hline PE, height, 12-lead ECG & $x$ & & & & & & & & & \\
\hline Weight & $x$ & & & & & & & & & $x$ \\
\hline Vital signs ${ }^{(a)}$ & $x$ & $x$ & $x$ & $x$ & $x$ & $x$ & $x$ & $x$ & $x$ & \\
\hline Ocular examination ${ }^{(b)}$ & $x$ & & $x$ & & $x$ & & $x$ & & $x$ & \\
\hline Haematology, serum biochemistry, urinalysis ${ }^{(c)}$ & $x$ & & & & $x$ & & & & $x$ & \\
\hline Interim PE & & & & & $x$ & & & & $x$ & \\
\hline Adverse events & & $x$ & $x$ & $x$ & $x$ & $x$ & $x$ & $x$ & $x$ & \\
\hline Skin snip ${ }^{(d)}$ & $x$ & & & & $x$ & & & & $x$ & \\
\hline Patch application & & OCP & & & & LTS-2 & & & & \\
\hline Reaction readout ${ }^{(\mathrm{e})}$ & & & $x$ & $x$ & & & $x$ & $x$ & & \\
\hline Skin punch biopsy & & & $x$ & & & & $x$ & & & \\
\hline \multicolumn{11}{|l|}{ Discharge } \\
\hline Day relative to OCP-patch application & -3 & 0 & 1 & 2 & 3 & 4 & 5 & 6 & 7 & 8 \\
\hline Day relative to LTS-2 patch application & -7 & -4 & & & & 0 & 1 & 2 & 3 & 4 \\
\hline
\end{tabular}

PE physical examination

${ }^{\text {(a) }}$ Pulse rate, blood pressure, respiratory rate, and oral temperature measured after at least 5 min supine. 6 times/day during screening period, 2times/day on days $1-8$

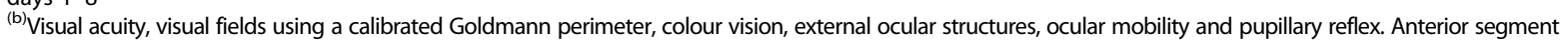
examination with Haag-Streit 900 slit-lamp. Microfilariae in anterior chamber counted after head-down positioning for 5 min. Count of living and dead microfilariae in cornea and punctuate opacities. Intraocular pressure, dilated fundus examination with direct and indirect ophthalmoscopy. Fundus photography and fluorescein angiography was planned only on subjects with abnormalities of visual function (visual acuity or visual fields) and was not indicated in any subject

${ }^{(c)}$ Samples obtained in fasting state. Haematology: complete blood cell count (CBC), haematocrit, haemoglobin, WBC with manual differential, platelet count. Serum chemistry: sodium, potassium, chloride, carbon dioxide, glucose, total protein, albumin, blood urea, creatinine, alkaline phosphatase, lactic dehydrogenase (LDH), total bilirubin, gamma-glutamyl transpeptidase (GGT), aspartate aminotransferase (AST/SGOT), and alanine aminotransferase (ALT/SGPT). Urinalysis: 10-parameter dipstick (specific gravity, $\mathrm{pH}$, protein, glucose, ketones, blood, bilirubin, urobilinogen, nitrite, leucocytes) and microscopic evaluation

${ }^{(d)}$ Two skin snips from right and left iliac crests using a $2 \mathrm{~mm}$ Holth or Walser-type corneoscleral punch. Each snip was weighed on an analytical balance and incubated overnight in isotonic saline in a well of a flat-bottomed microtitre plate. Emerged mf were counted under inverted microscope. The skin mf density at each site was calculated per mg skin. Screening skin snips were obtained on Day -3

${ }^{(\mathrm{e})}$ Local reaction reading on Day 2 and Day 6 occurred immediately after removal of the respective patch $24 \mathrm{~h}$ after its application and again $6 \mathrm{~h}$ later (i.e. $30 \mathrm{~h}$ after application of the respective patch and $6 \mathrm{~h}$ after its removal)

below the doses used for treatment of O.volvulus infected people (e.g. total doses of 100 to $6000 \mathrm{mg}$ [37], single dose of $100 \mathrm{mg}$ [17], daily doses of approximately $3 \mathrm{mg} / \mathrm{kg} /$ day for 7 days [39]). Subjects with microfilariae in the eyes, hyper-reactive onchodermatitis, skin lesions over the iliac crests, coincidental infection with Mansonella streptocerca, clinically significant ECG abnormalities, history of cardiac abnormalities or a history of alcohol or drug abuse were not eligible. The details of the procedures and laboratory tests conducted for assessing the eligibility of participants have been described previously [40] and are summarized in Table 1.

\section{Study design}

This was an open label study of the OCP-patch and the LTS-2 patch. Each patch was applied once in each of the 30 participants. Subjects were admitted to the OCRC four to five days before the $1^{\text {st }}$ patch application and remained in the centre until 8 days afterwards. The OCP-patch was applied to the left iliac crest on day 1 and removed after $24 \mathrm{~h}$. The LTS-2 patch was applied to the right iliac crest on day 5 and removed after $24 \mathrm{~h}$. All examinations conducted and their timing are shown in Table 1.

\section{DEC patches and patch application}

OCP-patch: The OCP-patch kit (provided by Dr. L. Toe, WHO Multi Disease Surveillance Center, Ouagadougou, Burkina Faso) consisted of $3 \mathrm{~cm} \times 2 \mathrm{~cm}$ pieces of filter paper (Whatman 3MM; Whatman International, Maidstone, UK), $9 \mathrm{~cm} \times 6 \mathrm{~cm}$ strips of perforated adhesive plaster, $25 \mathrm{~g}$ of diethylcarbamazine citrate salt (Sigma Chemical Corporation, St Louis, MO, USA) and $250 \mathrm{ml}$ of Nivea skin milk (Beiersdorf, Norwalk, CT, USA). The patches were prepared according to the instructions provided with the kit $[26,27]$. A $20 \%$ DEC lotion (w/v) was prepared by thoroughly mixing $25 \mathrm{~g}$ of DEC salt and $125 \mathrm{ml}$ of Nivea milk in a wide mouthed plastic container with a firm fitting cover. The container was labelled with the contents and date of preparation and kept in the refrigerator until used. As per the instructions in the kit, the solution is stable for 1 year in the refrigerator and for 6 months at room temperature in the shade. On the day of application, the patch was prepared and administered 
as follows: the lotion was left on a tray at $22-24{ }^{\circ} \mathrm{C}$ until it flowed freely out of the container and a small stainless steel gallipot was half filled with the solution. With a pair of dissecting forceps, a piece of filter paper was completely immersed into the DEC solution for around $10 \mathrm{~s}$, removed and any excess DEC lotion eliminated by sliding both surfaces of the filter paper on the edge of the gallipot. The filter paper was placed in the middle of the adhesive surface of the perforated plaster that had been pre-labelled with the participant number on the opposite surface. The plaster was held by the edges and the longitudinal axis applied firmly to the left iliac crest previously swabbed with $70 \%$ methylated spirit and allowed to dry. Based on the concentration of the DEC-nivea solution, the DEC molecular weight and the difference in weight of the dry and DEC solution soaked filter paper determined for 10 filter paper pieces, it was estimated that on average each filter paper contained approximately $40.8 \mathrm{mg}$ of DEC salt.

LTS-2 patches, provided by Lohmann Therapie Systeme, are around $2.9 \mathrm{~cm} \times 2.3 \mathrm{~cm}$ transparent films coated with $5.4 \mathrm{mg}$ of DEC on one surface (acceptable range as per manufacturing specifications: $4.6-6.2 \mathrm{mg}$ ). The DEC coated adhesive surface is protected by two rectangular pieces of aluminized film of unequal size with bossed edges. Each patch was sealed in a white envelope labelled with the batch number. The envelopes were kept at a temperature of $22-24{ }^{\circ} \mathrm{C}$. For LTS-2 patch application, the larger of the aluminized films over the DEC coated surface was pulled away, exposing part of the DEC coated surface. This was immediately applied to the skin previously swabbed with $70 \%$ methylated spirit and allowed to dry. While holding the film securely to the skin with one hand, the smaller piece of aluminium foil was removed, exposing the rest of the DEC surface which was pressed onto the skin. The patch was then held firmly in position for a few seconds.

All patches were applied with 2 min between participants beginning at $0700 \mathrm{~h}$. Subjects were advised not to bathe until after the removal of the DEC patch $24 \mathrm{~h}$ later.

At the time of this study, the stability data obtained by LTS supported stability for 12 months at $20-25{ }^{\circ} \mathrm{C}$. Further stability studies conducted by LTS confirmed LTS-2 patch long term stability. In conjunction with the results of the study described here, presented to the Technical Consultative Committee of APOC in March 2007 [41], this allowed the epidemiological evaluations in Senegal and Mali in January-February 2008 [5] to use LTS-2 patches from the batch used in this study.

\section{Outcomes}

Table 1 shows the timing and type of evaluations conducted.
Safety was assessed based on adverse events (AEs), i.e. unintended and unfavourable changes from pretreatment [42] in clinical and ocular symptoms, vital signs and laboratory indices (haematological, biochemical and urine). Symptoms were documented whenever they occurred and during formal enquiries conducted twice daily throughout the admission period. Vital signs were recorded at the same time, and whenever an adverse event was reported. The assessment of seriousness was conducted based on the criteria in ICH guidelines [42] and grading of the severity of AEs and causality attribution employed modifications of previously published criteria $[43,44]$. AEs that occurred on days 1 to 4 after OCPpatch application and on days 5 to 8 after the LTS-2 patch were regarded as potentially attributable to the patch applied. The decision on whether an $\mathrm{AE}$ was considered as related to the patch took into account the timing of AEs relative to patch application and the participant's state of health as well as the known effects of exposure to DEC [17-21].

Presence of diagnostic local skin reactions: According to the OCP-patch manual $[26,27]$, the local reactions are read $24 \mathrm{~h}$ after patch application. In the study of the LTS patch prototype (unpublished data), several subjects complained of increased local itching approximately $6 \mathrm{~h}$ after removal of the OCP-patch. Therefore, the presence, type and intensity of the reaction at the site of the OCP-patch and of the LTS-2 patch were read $24 \mathrm{~h}$ and $30 \mathrm{~h}$ after patch application. Scoring of the intensity of the OCP-patch reactions was as described previously [25-27] (Table 2). Because the reactions under the LTS-2 patch site were different from those under the OCP-patch, a scoring system was developed for the LTS-2 patch (Table 2). KA and NOO scored the

Table 2 Scoring of OCP and LTS-2 DEC patch skin reactions

\begin{tabular}{|c|c|c|c|}
\hline \multicolumn{2}{|c|}{ OCP DEC patch ${ }^{a}$} & \multicolumn{2}{|c|}{ LTS-2 DEC patch } \\
\hline Score & Criteria & Score & Criteria \\
\hline 0 & No rash & 0 & $\begin{array}{l}\text { No swelling; pin point } \\
\text { papules only }\end{array}$ \\
\hline 1 & $\begin{array}{l}1-3 \text { discrete, well formed } \\
\text { papules }\end{array}$ & 1 & $\begin{array}{l}<50 \% \text { of the patch } \\
\text { application area is covered } \\
\text { by swelling }\end{array}$ \\
\hline 2 & $\begin{array}{l}\text { 4-8 discrete, well formed } \\
\text { papules }\end{array}$ & 2 & $\begin{array}{l}\geq 50 \% \text { of patch application } \\
\text { area is covered by swelling } \\
\text { but an area without } \\
\text { swelling is present }\end{array}$ \\
\hline 3 & $\begin{array}{l}>8 \text { discrete, well formed } \\
\text { papules papules separated } \\
\text { by normal skin }\end{array}$ & 3 & $\begin{array}{l}\text { The outline of the patch } \\
\text { is completely covered } \\
\text { by a well defined swelling } \\
\text { (the outline lesion) }\end{array}$ \\
\hline 4 & $\begin{array}{l}\text { Coarse or confluent papules } \\
\text { or extensive oedema due } \\
\text { to conglomeration of } \\
\text { papules (peau d'orange) }\end{array}$ & & \\
\hline
\end{tabular}

${ }^{\mathrm{a} O C P}$ training manual $[26,27]$ 
reactions jointly without disagreements recorded as having to be resolved.

Potential DEC penetration into the tissue surrounding the patch area was assessed in two ways: the extent to which diagnostic rashes extended beyond the area under the patch and through skin $\mathrm{mf}$ densities in 1 skin snip obtained $1 \mathrm{~cm}$ from the patch application area on each of the two iliac crests on day 4 and day 8 .

Presence of indicators of microfilarial death (microfilarial fragments, intraepithelial abscesses and eosinophils) under the patch application area: Skin punch biopsies of $4 \mathrm{~mm}$ diameter were taken $30 \mathrm{~h}$ after patch application from the area under the OCP-patch in two participants and from the area under the LTS-2 patch in eight participants. All skin punch biopsies were performed under aseptic conditions in the OCRC minor surgery theatre. The patch reaction site was cleaned with an antiseptic and methylated spirit, anaesthetized with $2 \%$ xylocaine and a core of skin removed using a $4 \mathrm{~mm}$ skin biopsy punch (Stiefel Laboratorium GmbH, Mühlheimer Straße 231, 63075 Offenbach am Main, Germany). The biopsy site was secured with a single silk thread, covered with a sterile dressing and dressed until healed. The biopsy tissue was preserved in 10 times its volume of $4 \%(\mathrm{w} / \mathrm{v})$ buffered formaldehyde. All biopsies were provided at the same time to the parasitologist (trained in histopathology) in containers labelled only with the participant number. The parasitologist was thus blinded to the patch type. The biopsies were processed as for routine histopathology [45], stained with haematoxylin and eosin and six $4 \mu \mathrm{m}$ sections examined.

\section{Statistical methods}

The sample size of 30 participants provided a probability of $>0.95$ to detect at least 1 adverse event with a true frequency of $\geq 10 \%$.

Number analysed: All participants who qualified for the study received both patches and were included in the data analysis.

Safety analysis: The frequency and duration of adverse events occurring after the OCP-patch and after the LTS-2 patch and considered as related to patch administration by the investigator were compared using a paired $\mathrm{t}$-test.

Local skin reaction analysis: The positive readout rates at 24 and $30 \mathrm{~h}$ for each patch were compared using Fisher's Exact Test. The association between the positive readouts of the two patches was compared using McNemar's test.

Skin $\mathrm{mf}$ densities at the two iliac crests pre-patch administration were compared with a paired t-test. Skin $\mathrm{mf}$ densities between skin snip sites and time points and between time points for each skin snip site were compared with a one way ANOVA considering the different skin mf counts from each participant as repeated measures (Tukey's multiple comparison test).

Analyses were performed with PSPPIRE 7.10 (www.gnu. org) or GraphPad Prism version 6.02 for Windows (GraphPad Software, La Jolla California USA, www.graphpad. com).

\section{Results}

\section{Participant flow and baseline characteristics}

Thirty-seven volunteers gave informed consent and were screened. Fourteen women and 16 men were enrolled and completed the study as planned. Reasons for screen failure were: undetectable levels of skin $\mathrm{mf}$ (2), skin $\mathrm{mf}$ count $>20 \mathrm{mf} / \mathrm{mg}$ (4), microfilariae in the eye (1).

Table 3 shows the demographic and baseline characteristics of the 30 participants. The frequency of ocular symptoms present at baseline diminished over time without any intervention. Only 3/11 participants with ocular symptoms during screening had an ocular symptom (itching, discomfort (participants report they feel they have sand in the eyes without any evidence to that effect on ocular examination) or lacrimation) at the end of the study. There was no evidence of intraocular inflammation at any time during the study.

During screening, all participants were skin snip positive at the left iliac crest, while three were negative at the right iliac crest. On day 4, two of these three participants were skin snip positive at both crests, the other was skin snip negative at both crests. There was no significant difference between the skin $\mathrm{mf}$ levels at the right and left iliac crest.

\section{Ease of application of LTS-2 patch}

The LTS-2 patch was easily removed from its envelope with the gloved hand, and could be applied to the skin by an experienced operator within $10 \mathrm{~s}$. In 5 out of 30 participants the LTS-2 patch detached before $24 \mathrm{~h}$ and was secured with strips of plaster.

\section{Adverse events considered not related to patch application}

Events considered unreleated to patch application or study conduct by the investigators (KA and $\mathrm{NOO}$ ) were recorded in $21(70.0 \%)$ of the participants, including in 10 only after OCP-patch application, in 4 only after LTS-2 patch application and in 7 after both patch applications. Events included ocular itching, discomfort or lacrimation (symptoms frequently observed in subjects infected with $O$. volvulus, see results of baseline investigations, Table 3), different types of pain (body, waist, epigastric, abdominal, chest, ear, head), pyuria, hematuria, bodily weakness, cough, and chills. These events were mild and none required intervention. 
Table 3 Demographic and baseline characteristics of the 30 participants

\begin{tabular}{|c|c|c|c|}
\hline Demographics & $n(\%)$ & Ocular symptoms & $n(\%)$ \\
\hline Women & $16(53.3 \%)$ & Itching & $4(13.3)$ \\
\hline Mean ${ }^{a}$ (range) age women & $44(30-55)$ & Discomfort $^{c}$ & $1(3.3)$ \\
\hline \multirow[t]{3}{*}{ Mean ${ }^{a}$ (range) age men } & $34(22-55)$ & Lacrimation & $2(6.7)$ \\
\hline & & Itching + lacrimation & $1(3.3)$ \\
\hline & & Itching + discomfort ${ }^{c}$ & $1(3.3)$ \\
\hline \multirow[t]{2}{*}{ Microfilaremia } & Across both crests & Left iliac crest & Right iliac crest \\
\hline & & OCP-patch site & LTS-2 patch site \\
\hline Skin snip positive & 30 & 30 & 27 \\
\hline Mean $^{\mathrm{a}} \pm \mathrm{SD} \mathrm{mf} / \mathrm{mg}$ skin & $7.2 \pm 7.8$ & $7.7 \pm 8.1$ & $6.6 \pm 9.5$ \\
\hline Median & 4.58 & 4.95 & 3.0 \\
\hline Range $\mathrm{mf} / \mathrm{mg}$ skin $^{\mathrm{b}}$ & $0.2-36.8$ & $0.3-31.8$ & $0-47.7$ \\
\hline
\end{tabular}

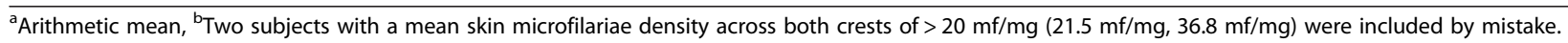

${ }^{\mathrm{C}}$ Participants report a feeling as if they had sand in the eye without any evidence of particulate matter on ocular examination

\section{Mazzotti reactions}

The Mazzotti reactions (other than the diagnostic local skin reaction) are summarized in Table 4. No ocular inflammation or change in visual function occurred after either patch. Changes in laboratory values were not considered clinically significant by the investigators
(KA and NOO). The most common Mazzotti reaction was itching. All itching was mild and resolved without treatment.

Figure 1 shows the difference between the duration of the respective patch site itching after the LTS-2 patch and the OCP-patch for each subject. The frequency and the

Table 4 Mazzotti reactions after OCP-patch and LTS-2 patch application

\begin{tabular}{|c|c|c|}
\hline Mazzotti reactions & After OCP-patch & After LTS-2 patch \\
\hline \multirow[t]{2}{*}{ Itching at patch application site: $n(\%)^{*}$} & \multirow[t]{2}{*}{19 (63.3\%) at OCP-patch site } & $6(20.0 \%)$ at LTS-2 patch site \\
\hline & & $3(10.0 \%)$ at OCP-patch site ${ }^{b}$ \\
\hline Start (hrs after patch application) $)^{a}$ Mean \pm SD & $12.6 \pm 13.4$ & $6.9 \pm 6.9$ at LTS-2 patch site \\
\hline \multirow[t]{2}{*}{ Start (hrs after patch application) ${ }^{\mathrm{a}}$ Range (Median) } & \multirow[t]{2}{*}{$0.8-52.0(8.2)$} & 1.5-19.4 (4.1) at LTS-2 patch site \\
\hline & & $0.1,0.5,4.1+36.1-$ at OCP-patch \\
\hline Duration (hrs): Mean $\pm \mathrm{SD}^{\mathrm{a},{ }^{* *}}$ & $8.9 \pm 11.8$ & $1.0 \pm 2.5$ at LTS2 patch \\
\hline Duration (hrs): Range (Median) & \multirow[t]{2}{*}{$0-56(7.63)$} & 0-8.9 (0) - at LTS-2 patch \\
\hline Duration (hrs) & & $1.1,4,6+12-$ at OCP-patch \\
\hline Itching involving the whole body: $n$ (\%) & $5(16.7)$ & $2(6.7 \%)$ \\
\hline Start (hrs after patch application) & $4.1,28.1,51.9,36.4,4.3$ & $5.7,13.2$ \\
\hline Duration (hrs) & $7.9,8.0,8.2,23.8,55.9$ & $6.3,15.0$ \\
\hline Itching at back & $1(3.3 \%)$ & 0 \\
\hline \multicolumn{3}{|l|}{ Other clinical Mazzotti reactions } \\
\hline Burning sensation at patch site ${ }^{c}$ & $2(6.7 \%)$ & 0 \\
\hline Pain at patch site & $1(3.3 \%)$ & 0 \\
\hline \multicolumn{3}{|l|}{ Haematological/biochemical reactions } \\
\hline Leucocytosis with increase in peripheral granulocytes & $4(13.3)$ & $6(20.0 \%)$ \\
\hline Increase in AST & $3(10 \%)^{d}$ & 0 \\
\hline Increase in ALT & $3(10 \%)^{d}$ & $4(13.3 \%)+2\left(6.7 \%{ }^{d}\right)$ \\
\hline Increase in ALP & 0 & $2(6.7 \%)$ \\
\hline
\end{tabular}

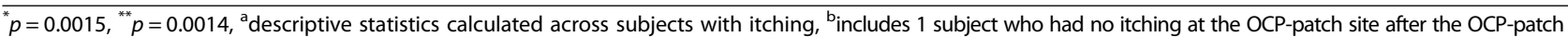
application, 'described by the participants as 'pepper on the skin', duration 3.3 and $6.4 \mathrm{~h}$, resp. ${ }^{\mathrm{d}}$ Elevations persisted into period after LTS-2 application and in 2 participants ALT elevation increased from grade 1 after OCP-patch application to grade 2 after LTS-2 patch application 


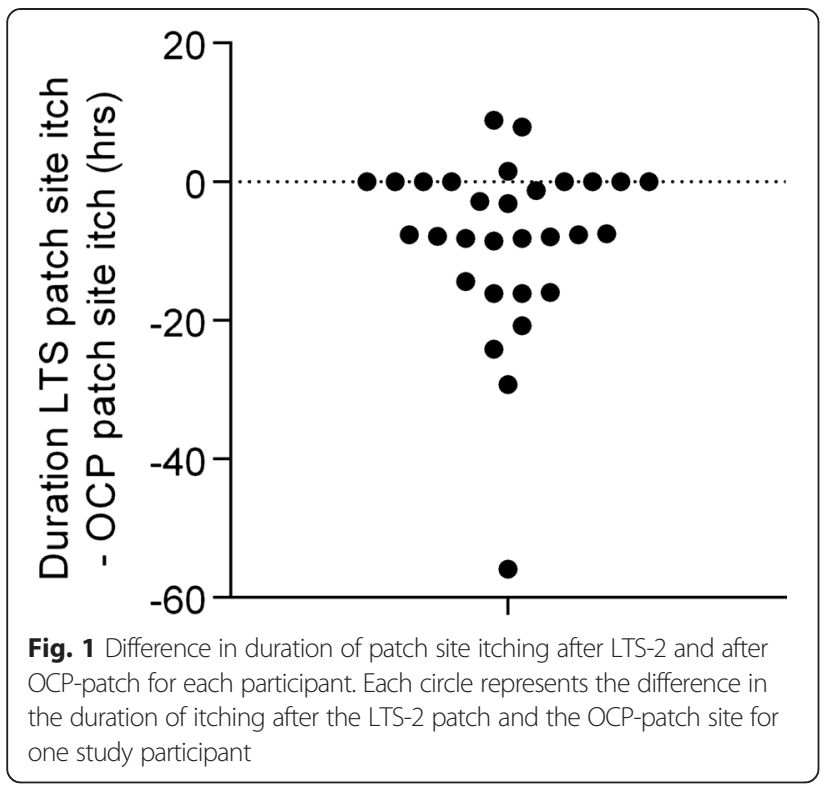

duration of patch site itching after the OCP-patch were significantly higher than after the LTS- 2 patch $(p=0.0015$ and $p=0.0014$, respectively).

\section{Changes in ocular microfilariae over the course of the study}

None of the participants had $\mathrm{mf}$ in the anterior chambers of the eyes at screening. One to three $\mathrm{mf}$ appeared in the anterior chamber of the eye of one participant on days 2, 4, 6 and 8; a single microfilaria appeared in the anterior chamber of the eye on day 2 in two participants and on day 6 and 8 in one participant each. This suggests that it is best to assume that microfilariae are present in the eye even if they are not visualized at the initial examination and skin $\mathrm{mf}$ densities are low.

\section{Characteristics of the local skin reaction under the patch sites}

The OCP-patch reaction: In 19/30 (63.3 \%) participants, the local reaction under the OCP-patch consisted mainly of well formed pinhead papules (Fig. 2 bottom) and could be scored based on the criteria reported previously [25-27]. These criteria are based on the counting of papules (scores 1-3) and the formation of a peau d'orange appearance caused by the coalescence of papules (score 4, Table 2). In 11/30 (36.7 \%) participants, the reaction under the OCP-patch did not match the previously reported characteristics [25-27] and papules smaller than the pinhead papules (named 'pinpoint' papules) seen under the majority of OCP patches were observed. The characteristics of the reactions are summarized in Table 5. Three days after patch application, the skin reaction was still easily visible in 19 participants
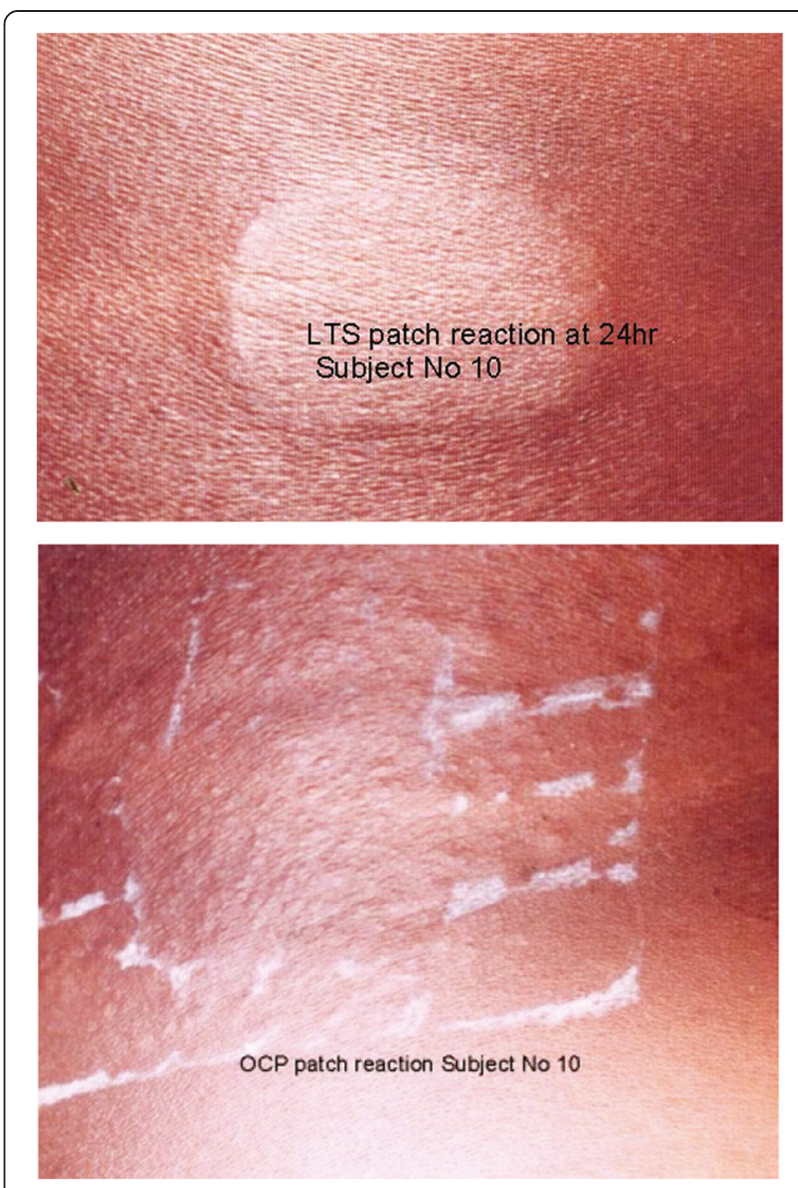

Fig. 2 Local reaction under the LTS 2 patch application area (outline lesion, top) and under and beyond the OCP-patch (bottom) in the same subject

(63.3\%) and persisted in one participant 1 week after application.

The LTS-2 patch reaction: The skin reaction which had developed under the LTS-2 patch sites did not consist of the pinhead papules typical for the OCP-patch reaction. Therefore, a detailed characterization of the reaction under the patch sites was performed ( Table 5).

The typical reaction, present in the majority of participants, presented as a well defined rectangular area that precisely matched the dimensions of the DEC impregnated area of the patch. This area was oedematous and studded with fine (pinpoint) papules (Fig. 2 top). This complex was termed the "outline lesion". It resembled a "subdued" peau d'orange. In a minority of participants, not the whole area was oedematous (Table 5). The percentage of the area that is oedematous is the basis for the proposed scoring system (Table 2).

The intensity of the oedema also varied, being very intense or intense, and hence visible at 'one glance' ('very easily visible reaction' or 'easily visible reaction' in Table 5), or being less intense and requiring attentive 
Table 5 Number (\%) of participants by characteristics of local reaction under the OCP and LTS-2 patches

\begin{tabular}{|c|c|c|c|c|}
\hline \multirow{2}{*}{$\begin{array}{l}\text { Characteristics } \\
\text { Definition of reaction }\end{array}$} & \multicolumn{2}{|c|}{ OCP-patch $(N=30)$} & \multicolumn{2}{|c|}{ LTS-2 patch $(N=30)$} \\
\hline & At $24 \mathrm{~h}$ & At $30 \mathrm{~h}$ & At $24 \mathrm{~h}$ & At $30 \mathrm{~h}$ \\
\hline None & $3(10.0)$ & $2(6.7)$ & $5(16.7)$ & 0 \\
\hline Oedema under the patch (any score) & NA & NA & $25(83.3)$ & $30(100)$ \\
\hline $100 \%$ of area oedematous (score 3 ) & NA & NA & $17(56.7)$ & $27(90.0)$ \\
\hline$>50 \%$ of area oedematous (score 2) & NA & NA & $4(13.3)$ & $3(10.0)$ \\
\hline$<50 \%$ of area oedematous (score 1) & NA & NA & $4(13.3)$ & 0 \\
\hline $0 \%$ of area oedematous (score 0 ) & NA & NA & $5(15.7)$ & 0 \\
\hline All reactions & $27(90.0)$ & $28(93.3)$ & $25(83.3)$ & $30(100)$ \\
\hline Very easily visible reaction & $18(60.0)$ & $24(80.0)$ & $22(73$. & $19(63.3)$ \\
\hline Easily visible reaction & $2(6.7)$ & $3(10.0)$ & 0 & $1(3.3)$ \\
\hline Attentive visual inspection required & $7(23.3)$ & $1(3.3)$ & $3(10.0)$ & $10(33.3)$ \\
\hline \multicolumn{5}{|l|}{ Character of papules } \\
\hline None & $3(10.0)$ & $2(6.7)$ & $5(16.7)$ & 0 \\
\hline Vague & $4(13.3)$ & $1(3.3)$ & $3(10.0)$ & 0 \\
\hline Pinheads & $16(53.3)$ & $16(53.3)$ & 0 & 0 \\
\hline Pinpoints & $7(23.3)$ & $11(36.7)$ & $19(63.3)$ & $29(96.7)$ \\
\hline Urticariform & 0 & 0 & $3(10.0)$ & $1(3.3)$ \\
\hline Extension beyond patch area & $2(6.7)$ & $8(26.7)$ & 0 & 0 \\
\hline
\end{tabular}

visual inspection of the patch area for diagnosis. The intensity of the oedema is not part of the proposed scoring system: it adds an element with potentially high inter-observer variability and even with $100 \%$ agreement between the two investigators (KA, NOO) in this study, did not improve the correlation between reaction score and skin mf levels (see below).

The oedema did not extend beyond the DEC impregnated area of the patch in any participant at either the $24 \mathrm{~h}$ or the $30 \mathrm{~h}$ reading.

The papules did not extend beyond the area covered by the patch either and did not conglomerate in any participant to form the "blood and thunder" oedema characteristic of the score 4 reaction after the OCPpatch. 'Pinhead' papules were not seen. Uncommonly, the papules were vague or shadowy and sometimes urticariform.

The outline lesion was present in 25 of 30 participants $(83.3 \%)$ at removal of the patch $24 \mathrm{~h}$ after administration. By $30 \mathrm{~h}$, all participants were positive (Table 5). In four participants the reaction was less developed at $30 \mathrm{~h}$ than at $24 \mathrm{~h}$, while in six others the reaction became better visible.

Three days after LTS-2 patch application, a skin reaction was visible in $5(16.7 \%)$ participants.

The proportion of participants with local reactions persisting to $\geq 3$ days after patch application was significantly higher after the OCP-patch than the LTS- 2 patch $(p<0.001)$.

\section{Skin microfilariae levels around $1 \mathrm{~cm}$ away from the} patch application area

Skin $\mathrm{mf}$ levels around $1 \mathrm{~cm}$ from the patch application area were measured on Day 0 (i.e. before OCP-patch application, on Day 4 (i.e. 3 days after the OCP patch application and before LTS-2 patch application) and on Day 8 (i.e. 3 days after application of the LTS- 2 patch). This was done with two objectives: a) to assess whether DEC penetrates beyond the patch application area in amounts significant enough to induce a reduction in skin $\mathrm{mf}$ levels (comparison of Day 0 and Day 4 measurement on the OCP-patch site for DEC penetration outside the OCPpatch area, comparison of Day 4 and Day 8 measurement for DEC penetration outside the LTS-2 patch area, and b) to estimate the number of skin mf levels for correlation with the patch scores (Day 0 and Day 4 skin mf levels for the OCP-patch and the LTS-2 patch, respectively).

For both patches, the mf levels in the snips taken after patch application were not consistently lower or higher than in the snip taken before patch application (Fig. 3). The descriptive statistics of the intra-individual differences between $\mathrm{mf}$ levels in snips taken before and after patch application calculated across all participants are shown in the lower panel of Table 6. These data suggest that the differences reflect local and/or temporal variation of $\mathrm{mf}$ density rather than changes induced by DEC present beyond the area exposed to the DEC in the patch. Consequently, the overall mean across all 6 snips taken from each participant is a better measure of the skin $\mathrm{mf}$ densities under the patch 


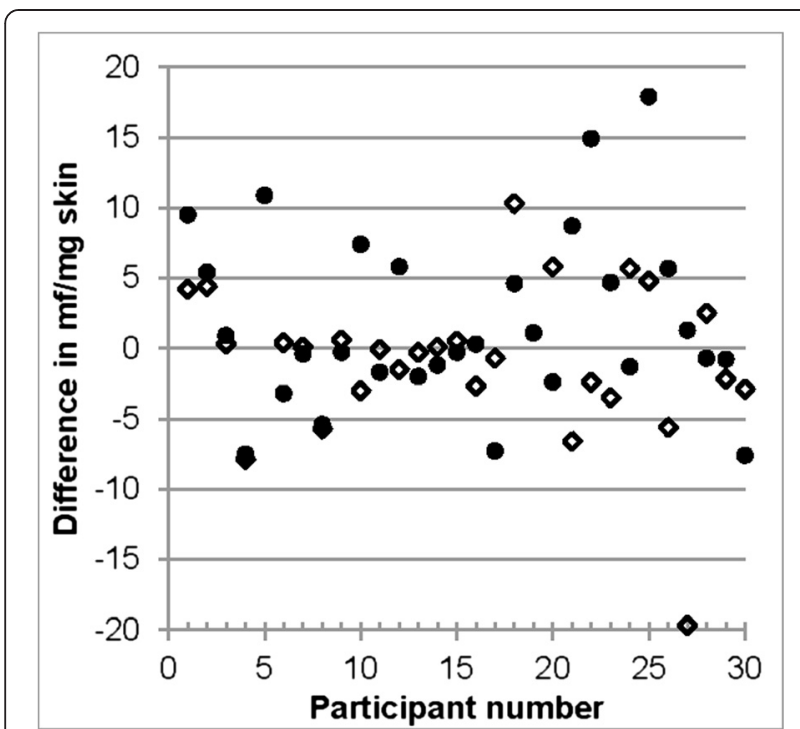

Fig. 3 Differences in skin microfilariae levels from snips taken approximately $1 \mathrm{~cm}$ away from the patch application area taken 3 days after and one day before application of the respective patch. Solid circles: OCP patch area, open diamonds: LTS-2 patch area

areas than are the $\mathrm{mf} / \mathrm{mg}$ counts of the individual skin snips.

\section{Percentage of participants with local skin reactions and correlation between local reaction scores and skin microfilariae density}

The percentage of participants with reactions at the 24 and $30 \mathrm{~h}$ reading was $90 \%$ and $93 \%$, respectively for the
OCP-patch and $83 \%$ and $100 \%$, respectively, for the LTS-2 patch (Table 5). The percentage of positive reactions to the two patches was not significantly different at either time point ( $p=0.71$ for 24 h reading, $p=0.49$ for $30 \mathrm{~h}$ reading).

There was no correlation between the OCP-patch or the LTS-2 patch score at either reading time and the skin $\mathrm{mf}$ levels, whether the overall mean skin $\mathrm{mf}$ density was considered (Fig. 4, Table 7) or the skin mf count in the snip taken before patch application at the respective crest (Table 7).

\section{Histopathology of skin punch biopsies from the reaction sites}

A local skin reaction was deemed to be definitely due to the local death of $\mathrm{mf}$ if microfilarial fragments, intraepithelial abscesses and eosinophils were found in the biopsies. This was the case in the two biopsies taken after the OCP-patch (arithmetic mean skin mf density across all skin snips in these two participants were 22.7 and $30.9 \mathrm{mf} / \mathrm{mg}$ skin) and in 4 of the 8 biopsies taken after the LTS-2 patch application (arithmetic mean skin $\mathrm{mf}$ densities across all 6 skin snips from each of these four participants 4.1, 13.07, 17.4, $19.9 \mathrm{mf} / \mathrm{mg}$ skin). The presence of $\mathrm{mf}$ fragments without intraepithelial abscesses was regarded as probably due to local death of $\mathrm{mf}$ and seen in one of the biopsies taken from the LTS-2 patch site (arithmetic mean skin mf density across all skin snips $12.3 \mathrm{mf} / \mathrm{mg}$ ). Presence of only eosinophils in the biopsy seen in $3 / 8$ biopsies of the LTS-2 patch site (arithmetic mean skin mf levels

Table 6 Microfilariae counts in snips taken around $1 \mathrm{~cm}$ from patch application areas before and after the application of the OCP and LTS-2 DEC patches

\begin{tabular}{|c|c|c|c|c|c|c|}
\hline \multirow[b]{3}{*}{ Study day } & \multicolumn{3}{|c|}{ Left iliac crest (OCP-patch site) } & \multicolumn{3}{|c|}{ Right iliac crest (LTS-2 patch site) } \\
\hline & \multicolumn{3}{|c|}{ Microfilariae/mg skin } & \multicolumn{3}{|c|}{ Microfilariae/mg skin } \\
\hline & Screening & Day 4 & Day 8 & Screening & Day 4 & Day 8 \\
\hline Days relative to patch application & -3 & 3 & 7 & -7 & -1 & 3 \\
\hline Mean $\pm S D^{a}$ & $7.73 \pm 8.09$ & $9.63 \pm 9.92$ & $6.63 \pm 8.80^{1}$ & $6.61 \pm 9.49$ & $8.06 \pm 9.55$ & $7.44 \pm 12.08$ \\
\hline Range $^{a}$ & $0.3-31.8$ & $0.0-36.9$ & $0.0-32.6$ & $0.0-47.7$ & $0.0-36.9$ & $0.5-62.0$ \\
\hline $\begin{array}{l}\text { Lowest count eliciting local reaction at } \\
24 \mathrm{hrs}^{\mathrm{a}}\end{array}$ & 0.3 & 0 & 0.6 & 0 & 0 & 0.5 \\
\hline $\begin{array}{l}\text { Highest count not eliciting local reaction } \\
\text { at } 30 \mathrm{~h}^{\mathrm{a}}\end{array}$ & 5.3 & 12.7 & 5.6 & NA & NA & NA \\
\hline Intra-individual difference in skin mf/mg & Day 4 - Screening & Day 8 - Screening & Day 8 - Day 4 & Day 4 - Screening & Day 8 - Screening & Day 8 - Day 4 \\
\hline Mean difference ${ }^{a}$ & 1.90 & -1.10 & -3.00 & 1.45 & 0.83 & -0.62 \\
\hline SD of difference & 6.27 & 5.67 & 6.12 & 8.46 & 10.26 & 8.58 \\
\hline Median of difference & 0.00 & -0.35 & -0.30 & 0.50 & 0.55 & -0.20 \\
\hline Range of difference & $-7.6-17.9$ & $-11.8-10.5$ & $-17.4-5.2$ & $-28.3-18.8$ & $-18.0-47.3$ & $-22.1-28.5$ \\
\hline
\end{tabular}

${ }^{a}$ Across snips from the respective location and time from all 30 participants. Screening $=$ Taken on admission and equivalent to day 0 for OCP-patch. Day $4=3$ days after application of OCP-patch and day 0 for LTS-2 patch. Day $8=3$ days after application of LTS-2 patch. SD standard deviation

${ }^{1} p=0.0228$ for comparison of Day 4 and Day 8 skin $\mathrm{mf}$ level at the left iliac crest, all other comparisons $p>0.2$ 


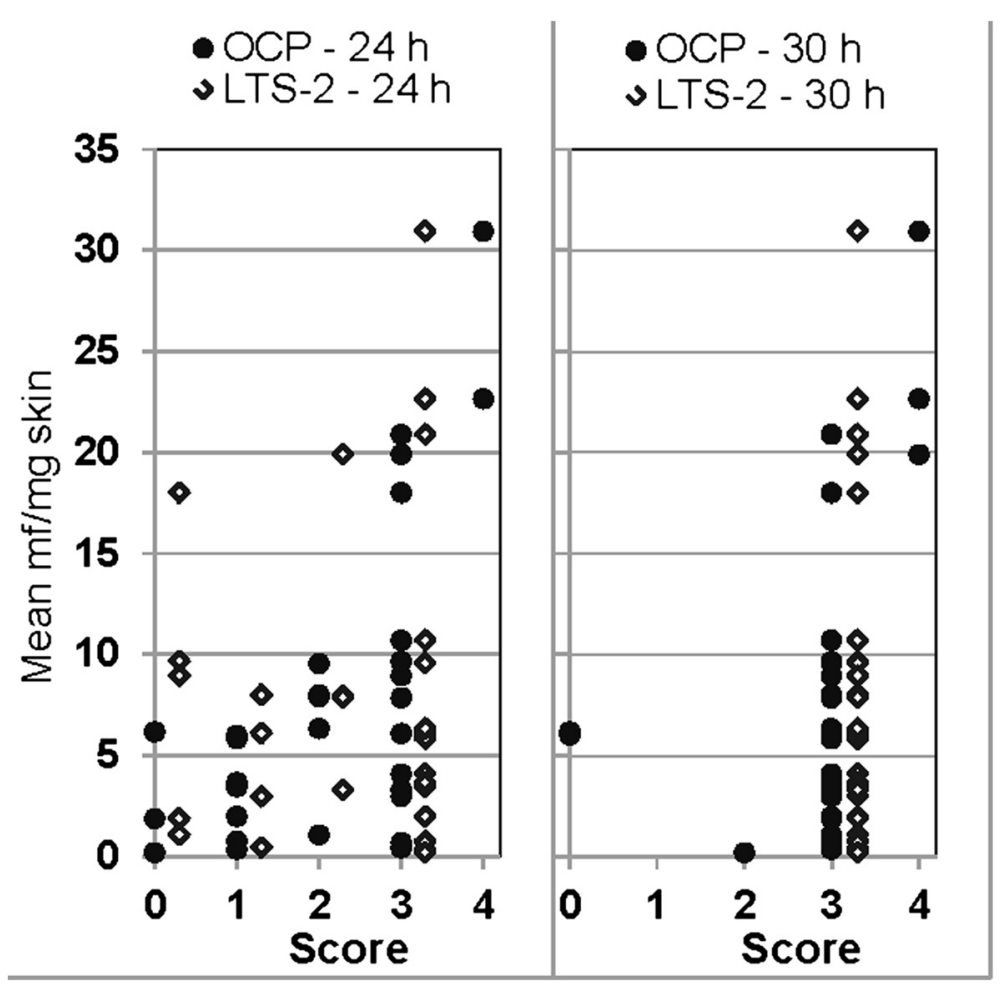

Fig. 4 OCP-patch and LTS-2 patch scores read at $24 \mathrm{~h}$ and $30 \mathrm{~h}$ vs. mean skin mf count across all 6 snips taken

across all 6 skin snips from each of these participants 0.9 , $4.0,7.7 \mathrm{mf} / \mathrm{mg}$ skin, reaction score 3 at both 24 and $30 \mathrm{~h}$ reading) was not regarded as evidence of local $\mathrm{mf}$ killing. Based on these criteria, evidence of local $\mathrm{mf}$ death was detected in 5 out of 8 biopsies taken after the LTS-2 patch.

\section{Discussion}

The primary aim of this clinical evaluation was to determine the safety, tolerability as well as the potential field utility (ease of application, presence and readout of diagnostic skin reaction) for the diagnosis of current $O$. volvulus infection of the LTS-2 patch in participants

Table 7 Proportion of subjects with local reaction by skin mf level measured $1 \mathrm{~cm}$ away from patch application area before application and by mean skin mf level across all skin snips taken

\begin{tabular}{|c|c|c|c|c|c|c|c|c|c|c|c|}
\hline \multicolumn{6}{|c|}{ OCP-patch } & \multicolumn{6}{|c|}{ LTS-2 patch } \\
\hline \multicolumn{2}{|c|}{$\begin{array}{l}\text { Skin } 1 \mathrm{~cm} \text { from patch area } \\
\text { pre application }\end{array}$} & \multicolumn{2}{|c|}{$\begin{array}{l}\% \text { of subjects by } \\
\text { score at } 24 \mathrm{~h}\end{array}$} & \multicolumn{2}{|c|}{$\begin{array}{l}\% \text { of subjects by } \\
\text { score at } 30 \mathrm{~h}\end{array}$} & \multicolumn{2}{|c|}{$\begin{array}{l}\text { Skin } 1 \mathrm{~cm} \text { from patch area } \\
\text { pre application }\end{array}$} & \multicolumn{2}{|c|}{$\begin{array}{l}\% \text { of subjects by } \\
\text { score at } 24 \mathrm{~h}\end{array}$} & \multicolumn{2}{|c|}{$\begin{array}{l}\% \text { of subjects by } \\
\text { score at } 30 \mathrm{~h}\end{array}$} \\
\hline $\mathrm{mf} / \mathrm{mg}$ & $\mathrm{N}$ & 1 & $\geq 2$ & 1 & $\geq 2$ & $\mathrm{mf} / \mathrm{mg}$ & $N$ & 1 & $\geq 2$ & 1 & $\geq 2$ \\
\hline$<1.0$ & 5 & 20.0 & 40 & 0 & 100 & $<1.0$ & 7 & 28.6 & 57.1 & 0 & 100 \\
\hline $1-5$ & 10 & 40.0 & 60 & 0 & 90.0 & $1-5$ & 9 & 0 & 77.8 & 0 & 100 \\
\hline$>5$ & 15 & 13.3 & 80 & 0 & 93.3 & $>5$ & 14 & 14.3 & 71.4 & 0 & 100 \\
\hline \multicolumn{6}{|l|}{ All snips } & \multicolumn{6}{|l|}{ All snips } \\
\hline $\mathrm{mf} / \mathrm{mg}$ & $N$ & 1 & $\geq 2$ & 1 & $\geq 2$ & $\mathrm{mf} / \mathrm{mg}$ & $\mathrm{N}$ & 1 & $\geq 2$ & 1 & $\geq 2$ \\
\hline$<1.0$ & 5 & 40.0 & 40.0 & 0 & 100 & $<1.0$ & 5 & 20 & 80 & 0 & 100 \\
\hline $1-5$ & 8 & 37.5 & 50.0 & 0 & 100 & $1-5$ & 8 & 12.5 & 71.4 & 0 & 100 \\
\hline$>5$ & 17 & 11.8 & 82.4 & 0 & 88.3 & $>5$ & 17 & 11.8 & 70.6 & 0 & 100 \\
\hline \multirow[t]{2}{*}{ Any } & 30 & 23.3 & 66.7 & 0 & 93.3 & Any & 30 & 13.3 & 70.0 & 0 & 100 \\
\hline & & \multicolumn{2}{|l|}{$\geq 1$} & \multicolumn{2}{|l|}{$\geq 1$} & & & \multicolumn{2}{|l|}{$\geq 1$} & \multicolumn{2}{|l|}{$\geq 1$} \\
\hline Any & 30 & \multicolumn{2}{|l|}{90} & \multicolumn{2}{|l|}{93.3} & Any & 30 & \multicolumn{2}{|l|}{83.3} & \multicolumn{2}{|c|}{100} \\
\hline
\end{tabular}


known to be infected compared to the OCP-patch as indirect indicators of whether the transdermal delivery of DEC of the LTS-2 patch was clinically significantly different from that of the OCP-patch.

No adverse events other than Mazzotti reactions were assessed as DEC exposure related. The most frequent Mazzotti reaction was mild itching. Itching was significantly less frequent after the LTS-2 patch than after the OCP-patch. Mazzotti laboratory value changes were neither considered clinically significant nor significantly different between the two patches. The rate of the diagnostic local skin reaction was not significantly different between the OCP-patch and the LTS-2 patch. Together, these data suggest that DEC penetration into the skin with the LTS-2 patch is neither significantly higher nor diagnostically significantly lower than that with the OCP-patch, hence qualifying the LTS-2 patch for large scale field evaluations.

Oral DEC treatment can lead to a combination of very severe Mazzotti reactions in multiple systems whose cumulative effects are dangerous and alarming in people with high skin $\mathrm{mf}$ densities [37]. The severity of Mazzotti reactions correlates with the intensity of infection in patients treated with the same oral DEC dose, and correlates with the oral DEC dose when patients with similar mf levels are compared, i.e. the reaction severity correlates with the amount of $\mathrm{mf}$ killed $[36,37]$. Thus, the safety profile of the LTS-2 patch in highly infected people potentially included in field evaluations and use depends on the total amount of mf killed after LTS-2 patch administration and the following needs to be considered: (1) the DEC dose, (2) the dose-response relationship for skin $\mathrm{mf}$ level reduction and (3) the number of $\mathrm{mf}$ that could be killed in highly infected people after LTS-2 patch application relative to the number of mf killed after oral DEC treatment of lightly infected patients in whom severe and dangerous Mazzotti reactions were not observed.

(1)LTS-2 patch DEC dose relative to DEC doses used in oral treatment. Total oral DEC doses used were in the range of $100 \mathrm{mg}$ to $6000 \mathrm{mg}$ [37], single doses e.g. $100 \mathrm{mg}$ [17], and daily doses e.g. $3 \mathrm{mg} / \mathrm{kg} /$ day for 7 days [39]. The maximum amount of DEC in a LTS-2 patch constitutes a total dose of only $6.2 \mathrm{mg}$ DEC or, at a body weight of e.g. $30 \mathrm{~kg}$, of only $0.2 \mathrm{mg} \mathrm{DEC} / \mathrm{kg}$ for 1 day. If skin penetration in people does not exceed that in the in-vitro human skin assay used by LTS during pharmaceutical development (3 mg over $24 \mathrm{~h}$, unpublished data), the total LTS-2 patch DEC dose available for systemic distribution is even lower. Any DEC becoming systemically available will be subject to the body's elimination mechanisms. The DEC half-life after oral administration is around 9-10 $\mathrm{h}[46,47]$. Orally administered DEC is absorbed almost completely and quickly with peak concentrations $1-4$ $\mathrm{h}$ after administration $[46,47]$. In the in vitro human skin permeation assay, a total of around $0.3 \mathrm{mg}$, $1.1 \mathrm{mg}$ and $3 \mathrm{mg}$ had permeated across the total patch surface area by $3 \mathrm{~h}, 8 \mathrm{~h}$ and $24 \mathrm{~h}$, respectively (unpublished results). These data suggest that, in contrast to absorption after oral administration, transdermal uptake is very slow which, in conjunction with ongoing DEC elimination, further reduces the maximum amount of DEC after the LTS-2 patch available for a systemic effect.

(2)Dose-response curve for skin mf level reductions. The total oral DEC dose that results in a $90 \%$ skin $\mathrm{mf}$ level reduction from baseline by 1 week after treatment was estimated at 500-600 mg. The doseresponse curve is exponential with a total dose of $100 \mathrm{mg}$ eliminating around $66 \%$ of $\mathrm{mf}$ from the skin [37]. Even if the total $6.2 \mathrm{mg}$ DEC in the LTS-2 patch became systemically available, it could consequently induce the death of only a small fraction of $\mathrm{mf}$. The skin snips obtained approximately $1 \mathrm{~cm}$ from the patch areas did not suggest that the LTS-2 patch (or the OCP-patch) led to DEC concentrations outside the patch area sufficient to result in measurable skin mf level reductions (Table 6, Fig. 3).

(3) Number of mf under the LTS-2 patch area in highly infected individuals relative to the number of $\mathrm{mf}$ killed after oral DEC treatment in lightly infected people in whom dangerous Mazzotti reactions have not been reported. Assuming a highly infected person with an average skin $\mathrm{mf}$ density of 2000/snip (i.e. approximately $2000 \mathrm{mf} / 4 \mathrm{~mm}^{2}$ skin surface area for snipping with a $2 \mathrm{~mm}$ Holth punch), 300,000 microfilariae are under the $6 \mathrm{~cm}^{2} \mathrm{DEC}$-impregnated LTS-2 patch area whose death could be induced. For comparison, assuming a very lightly infected person with an average skin $\mathrm{mf}$ density of only $1 /$ snip $\left(1 / 4 \mathrm{~mm}^{2}\right.$ skin surface area), and a body surface area of $1.0 \mathrm{~m}^{2}(30 \mathrm{~kg}, 123 \mathrm{~cm})$ or $1.7 \mathrm{~m}^{2}$ $(60 \mathrm{~kg}, 171 \mathrm{~cm})$, the number of skin $\mathrm{mf}$ that could be killed by oral DEC treatment is 250,000 and 425,000 , respectively.

These considerations suggest that the number of $\mathrm{mf}$ killed after LTS-2 patch application in highly infected people is unlikely to exceed the number of $\mathrm{mf}$ killed after oral DEC treatment of lightly infected people in whom severe Mazzotti reactions in multiple systems have not been observed. Consequently, development of dangerous reactions when the LTS-2 patch is used in highly infected people is very unlikely, while more severe itching and rash than observed in this study is likely. 
Application of the LTS-2 patch was easy and can be done within 10 s. Five out of 30 (16.7 \%) LTS-2 patches detached before the $24 \mathrm{~h}$ reading. During use of the LTS-2 patch in the epidemiological evaluations in Mali and Senegal up to one third of the LTS- 2 patches had partly or completely detached before the reading of the reaction at $24 \mathrm{~h}$ [5]. The detachment rate differed between countries (0/775 (0 \%) in Senegal, 382/1508 (25.3\%) in Mali, Hans Remme, report to the Technical Consultative Committee of APOC). The LTS-2 patch uses a pressure-sensitive adhesive. It is not possible to assess now whether variability in the duration and/or firmness with which the patches were applied contributed to the variable detachment rates. Training for future use will have to stress the importance of the subject applying light pressure for $10 \mathrm{~s}$ after application of the LTS- 2 patch and the difference between application of this and a conventional plaster. Reinforcement of patch adhesion with a strip of conventional plaster as recommended in the OCP-patch manual $[26,27]$ could also be considered for large scale LTS-2 patch use.

The skin reaction under the LTS-2 patch was very different from that under the OCP-patch. Based on the data from this study, the reading of the LTS- 2 reaction is best done by examination for the presence of the pinpoint papule-studded oedematous area under the patch. The significance of the pinpoint papules is currently unknown and therefore the presence of only pinpoint papules without oedema is not regarded as indicative of the presence of microfilariae (score 0, Table 2). None of the 2116 skin snip negative participants examined in Mali and Senegal who were also examined via the LTS-2 patch had a skin reaction [5]. This suggests that the LTS- 2 patch does not elicit a local reaction in the absence of skin microfilariae. Training (as conducted by OCRC staff before LTS-2 patch use in the epidemiological evaluations in Senegal and Mali) and attention to detail during the reading of the reaction will be important to ensure recognition of all LTS-2 reactions to avoid false negatives.

In $12 / 30(40 \%)$ of participants the LTS-2 score increased from 0,1 or 2 at the $24 \mathrm{~h}$ to 3 at the $30 \mathrm{~h}$ reading. Ten of these 12 participants $(83 \%)$ had a mean skin $\mathrm{mf}$ level across all skin snips taken of $<10 \mathrm{mf} / \mathrm{mg}$. Increase in scores from the $24 \mathrm{~h}$ to the $30 \mathrm{~h}$ examination were also seen with the OCP-patch, consistent with previous reports of higher sensitivity (\% of positive reactions in infected participants) and intensity of reaction at $48 \mathrm{~h}$ than $24 \mathrm{~h}$ reading [25].

The underlying basis of the skin reactions was examined through skin punch biopsies from 2/30 OCP-patch and 8/30 LTS-2 patch sites. In 3/8 biopsies from LTS-2 patch sites no intra-epidermal abcesses and/or microfilariae fragments supporting a DEC effect on local microfilariae were detected. These three biopsies were from participants with low skin $\mathrm{mf}$ levels (mean of $<8 \mathrm{mf} / \mathrm{mg}$ skin across all 6 skin snips taken). The commensurate low density of any microfilariae fragments that may have been present under the patch area may have been below the detection limit achievable with examination of six $4 \mu \mathrm{m}$ slices from a $4 \mathrm{~mm}$ diameter punch biopsy. Further biopsy studies need to be undertaken to better define the pathogenesis of the local reaction and to assess the potential for false positives.

Large scale evaluation with $24 \mathrm{~h}$ and $30 \mathrm{~h}$ readings in a population with low levels of skin microfilariae (e.g. $>0$ to $10 \mathrm{mf} / \mathrm{mg}$ ), ideally from an area co-endemic for other filarial species and incorporating other field-suitable and, if feasible, 'research only' tests for detection of current and past $O$. volvulus infection (e.g. OV 16 antibody detection, detection of $O$. volvulus DNA in skin snips via polymerase chain reaction), are recommended to define the sensitivity of the LTS-2 patch and to determine its specificity. The data will provide the basis for onchocerciasis control programme decisions on how to integrate the LTS-2 patch into monitoring of prevalence of $O$. volvulus infection, in particular residual prevalence in areas under long term CDTI where it is important to diagnose only active infection. Large scale evaluation of the LTS-2 patch in areas with different levels of prevalence of $O$. volvulus infection was also recommended by the APOC Technical Consultative Committee when it advised APOC to set up an agreement with LTS to provide the LTS-2 patches at low cost [48]. The LTS-2 patch is not available commercially but manufactured by LTS at the request of WHO and provided to WHO at cost. Countries can request patches from WHO.

\section{Conclusions}

The results from this study suggest that the LTS-2 patch has a safety and tolerability profile similar to and possibly better than that of the OCP-patch and that it elicits local skin reactions in a comparable proportion of patently infected individuals. This suggests that the transdermal delivery of DEC by the LTS-2 patch is comparable to that of the OCP-patch which qualifies the LTS-2 patch for large scale evaluations to determine its sensitivity and specifity.

\section{Competing interests \\ The authors declare that they have no competing interests.}

\section{Authors' contributions}

Conceived and designed the experiments: KA, JKLH. Performed the study: KA, NOO, SKA. Analysed and interpreted the data: KA, ACK. Drafted the manuscript: KA, ACK, JKLH. Given final approval of the manuscript: NOO, SKA, JKLH, ACK.

\section{Acknowledgements}

We recognize the contributions of the entire OCRC Hohoe staff, especially Dr. Mahmood Seidu and the study coordinator Ms. Vivian Kumah. We are particularly grateful to all participants in the study for their co-operation. We 
thank Dr. L. Toe from the WHO Multi-Disease Surveillance Center in Ouagadougou, Burkina Faso, for provision of the OCP-patch kit.

\section{Funding}

KA NOO and SKA conducted this study with funds provided by the UNICEF/ UNDPNorld Bank/World Health Organization Special Programme for Research and Training in Tropical Diseases (WHO/TDR, http://www.who.int/tdr/en/, grant ID 980819) with funds from WHO/TDR and the African Programme for Onchocerciasis Control. JKLH was and ACK is an employee of WHO/TDR. LTS Lohmann Therapie Systeme AG, Andernach, Germany developed and provided the LTS-2 patches for this study at no cost. LTS did not play a role in the design, conduct, analysis or writing of the manuscript of this study, nor in the decision to publish.

\section{Author details}

${ }^{1}$ Onchocerciasis Chemotherapy Research Centre, Hohoe, Ghana. ${ }^{2}$ Department of Microbiology, University of Ghana Medical School, Accra, Ghana. ${ }^{3}$ UNICEF/UNDP/World Bank/ WHO Special Programme for Research and Training in Tropical Diseases, World Health Organization, Geneva, Switzerland.

Received: 26 May 2015 Accepted: 28 September 2015 Published online: 09 October 2015

\section{References}

1. African Programme for Onchocerciasis Control (APOC). Final communiqué of the 11th session of the joint action forum (JAF) of APOC. 2005 http://www.who.int/apoc/about/structure/jaf/jaf11_final_communique.pdf, accessed 21 Sept. 2015.

2. Noma M, Nwoke BE, Nutall I, Tambala PA, Enyong P, Namsenmo A, et al. Rapid epidemiological mapping of onchocerciasis (REMO): its application by the African Programme for Onchocerciasis Control (APOC). Ann Trop Med Parasitol. 2002;96 Suppl 1:S29-39.

3. Coffeng LE, Stolk WA, Zoure HG, Veerman JL, Agblewonu KB, Murdoch ME, et al. African programme for onchocerciasis control 1995-2015: modelestimated health impact and cost. PLoS Negl Trop Dis. 2013:7:e2032

4. Eberhard M. Progress toward elimination of onchocerciasis in the americas - 1993-2012. MMWR Morb Mortal Wkly Rep. 2013;62:405-8.

5. Diawara L, Traore MO, Badji A, Bissan Y, Doumbia K, Goita SF, et al. Feasibility of onchocerciasis elimination with ivermectin treatment in endemic foci in Africa: first evidence from studies in Mali and Senegal. PLoS Negl Trop Dis. 2009;3:e497.

6. Traore MO, Sarr MD, Badji A, Bissan Y, Diawara L, Doumbia K, et al. Proof-of-principle of onchocerciasis elimination with ivermectin treatment in endemic foci in Africa: final results of a study in Mali and Senegal. PLoS Negl Trop Dis. 2012;6:e1825

7. Boussinesq M, Chippaux JP, Ernould JC, Quillevere D, Prod'hon J. Effect of repeated treatments with ivermectin on the incidence of onchocerciasis in northern Cameroon. Am J Trop Med Hyg. 1995;53:63-7.

8. Katabarwa M, Eyamba A, Habomugisha P, Lakwo T, Ekobo S, Kamgno J, et al. After a decade of annual dose of mass ivermectin treatment in Cameroon and Uganda, onchocerciasis transmission continues. Trop Med Int Health. 2008;13(9):1196-203.

9. Tekle AH, Elhassan E, Isiyaku S, Amazigo UV, Bush S, Noma M, et al. Impact of long-term treatment of onchocerciasis with ivermectin in Kaduna State, Nigeria: first evidence of the potential for elimination in the operational area of the African Programme for Onchocerciasis Control. Parasit Vectors. 2012;5:28.

10. African Programme for Onchocerciasis Control (APOC): Final Communiqué, Eighteenth Session of the Joint Action Forum 11-13 December 2012. [http:// www.who.int/apoc/publications/recommendations/en/index.html, accessed 21 Sept. 2015]; 2012.

11. Awadzi K, Roulet $H$, Bell DR. The chemotherapy of onchocerciasis V. A standard method for the determination of microfilarial density in skin snips. Ann Trop Med Parasitol. 1980;74:363-6.

12. Awadzi K, Opoku NO, Addy ET, Quartey BT. The chemotherapy of onchocerciasis. XIX: The clinical and laboratory tolerance of high dose ivermectin. Trop Med Parasitol. 1995;46:131-7.

13. Awadzi K, Opoku NO, Attah SK, Lazdins-Helds J, Kuesel AC. A randomized, single-ascending-dose, ivermectin-controlled. Double-Blind Study of
Moxidectin in Onchocerca volvulus Infection PLoS Negl Trop Dis. 2014;8:e2953.

14. Remme J, Baker RH, DeSole G, Dadzie KY, Walsh JF, Adams MA, et al. A community trial of ivermectin in the onchocerciasis focus of Asubende, Ghana. I. Effect on the microfilarial reservoir and the transmission of Onchocerca volvulus. Trop Med Parasitol. 1989;40:367-74.

15. Mazzotti L. Possibilidad de utilizar como medio diagnostico en la onchocercosis, las reacciones alergicas consecutivas a la administracion de 'Hetrazan'. Rev Inst Salubr Enferm Trop. 1948;9:235-7.

16. Buck AA. Onchocerciasis. Symptomatology, pathology, diagnosis. Geneva: World Health Organization; 1974.

17. Bryceson AD, Warrell DA, Pope HM. Dangerous reactions to treatment of onchocerciasis with diethylcarbamazine. Br Med J. 1977;1:742-4.

18. Bird AC, el-Sheikh $H$, Anderson J, Fuglsang $H$. Changes in visual function and in the posterior segment of the eye during treatment of onchocerciasis with diethylcarbamazine citrate. Br J Ophthalmol. 1980;64:191-200.

19. Bird AC, el-Sheikh H, Anderson J, Fuglsang H. Visual loss during oral diethylcarbamazine treatment for onchocerciasis. Lancet. 1979;2:46.

20. World Health Organization: Onchocerciasis and its Control. Report of a WHO Expert Committee on Onchocerciasis Control. Geneva: World Health Organization; 1995.

21. World Health Organization: WHO Expert Committee on Onchocerciasis, 3rd Report. Geneva: World Health Organization; 1987.

22. Kilian HD. The use of a topical Mazzotti test in the diagnosis of onchocerciasis. Trop Med Parasitol. 1988;39:235-8.

23. Newland HS, Kaiser A, Taylor HR. The use of diethylcarbamazine cream in the diagnosis of onchocerciasis. Trop Med Parasitol. 1987;38:143-4.

24. Stingl P, Ross M, Gibson DW, Ribas J, Connor DH. A diagnostic "patch test" for onchocerciasis using topical diethylcarbamazine. Trans R Soc Trop Med Hyg. 1984;78:254-8.

25. Toe L, Adjami AG, Boatin BA, Back C, Alley ES, Dembele N, et al. Topical application of diethylcarbamazine to detect onchocerciasis recrudescence in west Africa. Trans R Soc Trop Med Hyg. 2000;94:519-25.

26. World Health Organization/OCP. Epidemiological Surveillance: DiethylCarbamazine Patch Method, Field work and training manual. 2002. http://www.who.int/apoc/publications/guidefortraindec_patch/en/ accessed 21 Sept. 2015.

27. World Health Organization/OCP. Test de pansement à la diethylcarbamazine. Guide pratique pour la formation et la conduite du travail sur le terrain. 2002. http://www.who.int/apoc/publications/ guidefortraindec_patch/fr/, accessed 21 Sept. 2015.

28. Ozoh G, Boussinesq M, Bissek AC, Kobangue L, Kombila M, Mbina JR, et al. Evaluation of the diethylcarbamazine patch to evaluate onchocerciasis endemicity in Central Africa. Trop Med Int Health. 2007;12:123-9.

29. Toe L, Boatin BA, Adjami A, Back C, Merriweather A, Unnasch TR. Detection of Onchocerca volvulus infection by 0-150 polymerase chain reaction analysis of skin scratches. J Infect Dis. 1998;178:282-5.

30. Zimmerman PA, Guderian RH, Aruajo E, Elson L, Phadke P, Kubofcik J, et al. Polymerase chain reaction-based diagnosis of Onchocerca volvulus infection: improved detection of patients with onchocerciasis. J Infect Dis. 1994;169:686-9.

31. Vincent JA, Lustigman S, Zhang S, Weil GJ. A comparison of newer tests for the diagnosis of onchocerciasis. Ann Trop Med Parasitol. 2000;94:253-8.

32. Ayong LS, Tume CB, Wembe FE, Simo G, Asonganyi T, Lando G, et al. Development and evaluation of an antigen detection dipstick assay for the diagnosis of human onchocerciasis. Trop Med Int Health. 2005; 10:228-33.

33. Bradley JE, Unnasch TR. Molecular approaches to the diagnosis of onchocerciasis. Adv Parasitol. 1996;37:57-106.

34. Oguttu D, Byamukama E, Katholi CR, Habomugisha P, Nahabwe C, Ngabirano M, et al. Serosurveillance to monitor onchocerciasis elimination: the ugandan experience. Am J Trop Med Hyg. 2014;90:339-45.

35. World Health Organization. Quality assurance of pharmaceuticals. A compendium of guidelines and related materials, Good manufacturing practices and inspection, vol. 2. 2nd ed. Geneva: World Health Organization; 2007.

36. Francis $\mathrm{H}$, Awadzi $\mathrm{K}$, Ottesen EA. The Mazzotti reaction following treatment of onchocerciasis with diethylcarbamazine: clinical severity as a function of infection intensity. Am J Trop Med Hyg. 1985;34:529-36.

37. Awadzi K, Gilles HM. Diethylcarbamazine in the treatment of patients with onchocerciasis. Br J Clin Pharmacol. 1992;34:281-8.

38. Fulford AJ, Macfarlane SB, Awadzi K, Bell DR, Gilles HM. The chemotherapy of onchocerciasis. XII. The prediction of microfilarial loads in patients with 
onchocerciasis after treatment with diethylcarbamazine in northern Ghana. Ann Trop Med Parasitol. 1987:81:701-11.

39. Ackerman SJ, Kephart GM, Francis H, Awadzi K, Gleich GJ, Ottesen EA. Eosinophil degranulation. An immunologic determinant in the pathogenesis of the Mazzotti reaction in human onchocerciasis. J Immunol. 1990:144:3961-9.

40. Awadzi K, Edwards G, Opoku NO, Ardrey AE, Favager S, Addy ET, et al. The safety, tolerability and pharmacokinetics of levamisole alone, levamisole plus ivermectin, and levamisole plus albendazole, and their efficacy against Onchocerca volvulus. Ann Trop Med Parasitol. 2004;98:595-614.

41. African Programme for Onchocerciasis Control (APOC). Report of the twenty-fourth session of the Technical Consultative Committee March 2007. 2007.

42. ICH (International Conference on Harmonization of Technical Requirements for Registration of Pharmaceuticals for Human Use). Guideline for Good Clinical Practice, E6, R1, 1996. 1996. www.ich.org, accessed 21 Sept. 2015

43. Awadzi K. The chemotherapy of onchocerciasis II. Quantitation of the clinical reaction to microfilaricides. Ann Trop Med Parasitol. 1980;74:189-97.

44. Hero M, Bird AC, Awadzi K. Quantification of the ocular reactions to microfilaricides in the chemotherapy of onchocerciasis. Eye (Lond). 1992;6(Pt 1):93-6.

45. Awadzi K, Attah SK, Addy ET, Opoku NO, Quartey BT. The effects of high-dose ivermectin regimens on Onchocerca volvulus in onchocerciasis patients. Trans R Soc Trop Med Hyg. 1999;93:189-94.

46. Edwards G, Awadzi K, Breckenridge AM, Gilles HM, Orme ML, Ward SA. Diethylcarbamazine disposition in patients with onchocerciasis. Clin Pharmacol Ther. 1981;30:551-7.

47. Shenoy RK, Suma TK, John A, Arun SR, Kumaraswami V, Fleckenstein LL, et al. The pharmacokinetics, safety and tolerability of the co-administration of diethylcarbamazine and albendazole. Ann Trop Med Parasitol. 2002:96:603-14

48. African Programme for Onchocerciasis Control (APOC): Report of the twenty-eighth session of the Technical Consultative Committee (TCC), Ouagadougou 09-14 March 2009. Ouagadougou: [http://www.who.int/ apoc/about/structure/tcc/en/ accessed 21 Sept. 2015]; 2009.

\section{Submit your next manuscript to BioMed Central and take full advantage of:}

- Convenient online submission

- Thorough peer review

- No space constraints or color figure charges

- Immediate publication on acceptance

- Inclusion in PubMed, CAS, Scopus and Google Scholar

- Research which is freely available for redistribution 